\title{
NARRATIVAS PINTADAS, PINTURAS NARRADAS: A CARIDADE SEGUNDO PROUST E GIOTTO
}

\section{PAINTED NARRATIVES, NARRATED PAINTINGS: CHARITY}

ACCORDING TO PROUST AND GIOTTO

Hêmille Raquel Santos Perdigão*
* hrsperdigao@yahoo.com.br

Mestranda em Letras: Estudos da Linguagem na Universidade Federal Ouro Preto.
Resumo: No século $X X$ as alegorias do pintor italiano Giotto aparecem nas páginas de No Caminho de Swann, de Marcel Proust. O narrador faz uma reflexão sobre a alegoria da caridade de Giotto, comparando-a a uma criada de cozinha de sua famí lia, e expõe sua opinião de que a Caridade de Giotto aparenta não ter caridade. $O$ presente trabalho objetiva responder aos seguintes questionamentos: havendo tantas outras alegorias que, de fato, se assemelhavam mais à ideia de caridade do narrado proustiano, por que Swann associa a criada logo à Caridade sem caridade? E por que a Caridade de Giotto se distancia tanto das outras alegorias homonimas? A conclusão é que o afresco do outras a Eoris homonimas? A conclusăo é que o afreco do italiano teve como modelo a figura de Beatriz em Vida Nova de Dante Alighieri. Dessa forma, a Caridade de Giotto foi pintada partir da narrativa de Dante Alighieri e, na narrativa de Proust, a criada de cozinha foi descrita a partir da pintura de Giotto.

Palavras-chave: écfrase; compositio; Caridade; Giotto; Proust.
Abstract: In the twentieth century, the allegories of the Italian painter Giotto appear on Marcel Proust's Swann's Way. The narrator brings some considerations about Giotto's allegory of charity, comparing it to his family's kitchen-maid and exposes his opinion that Giotto's Charity seems not to have charity. The present work aims to answer the following questions: among so many allegories closer to the narrator's idea of charity, why does the character Swann associate the kitchen-maid to the 'Charity without charity'? And why is Giotto's Charity so different from the other allegories? The conclusion was that the Italian fresco whe Therefor Therefore, Giotto's Charity was painted from Dante Alighieri's narrative and, in Proust's narrative, the kitchen-maid was described from Giotto's painting

Keywords: ekphrasis; compositio; charity; Giotto; Proust 


\section{INTRODUÇÃO}

A alegoria (gregos allós = outro; agourein $=$ falar) diz b para significar a. (HANSEN, 2006, p. 7).

A alegoria é a metáfora continuada como tropo de pensamento, e consiste na substituição do pensa mento em causa por outro pensamento, que está ligado, numa relação de semelhança, a esse mesmo pensamento. (LAUSBERG apud HANSEN, 2006, p. 7)

As definições acima se referem à alegoria, modo de interpretação desde a Antiguidade e, a partir da Idade Média, modo de criação intrínseco à Literatura e a outras Artes. Walter Benjamin defende que é comum que as alegorias sejam compostas não só por objetos como ta mbém por personificações, cuja "função não é a de personificar o mundo das coisas, mas a de dar forma mais imponente às coisas, vestindo-as de personagens." (BENJAMIN, 2011, p. 199). O conceito de alegoria de Benja min se baseia, ta mbém, em um olhar para o passado, visto que a obra em que ele aborda o tema, Origem do drama trágico alemão, traz a ideia da alegoria com o intuito de buscar a origem de algo, como está dito no próprio título. Assim, a busca benjaminiana por alegorias marca uma busca por algo que eternize o que foi efêmero.
Erwin Panofsky, por sua vez, tendo como referência a História da Arte, discorre sobre a alegoria composta por personificação e símbolo:

Imagens que veiculam a ideia, não de objetos e pessoas concretos e individuais (tais como São Bartolomeu, Vênus, Mrs. Jones ou o Castelo de Windsor), mas de noções gerais e abstratas como Fé, Luxúria, Sabedoria, etc, são chamadas personificações ou símbolos. [...] Assim, alegorias [...] podem ser definidas como combinações de personificações e/ou símbolos. [...] Uma estória pode comunicar, também, uma ideia alegórica [...] ou pode ser concebida como a prefiguração de uma outra. (PANOFSKY, 1979, p. 51)

Panofsky entra em uma questão importante: a possibilidade de uma história poder comunicar uma ideia alegórica e, mais, a possibilidade de preceder uma imagem alegórica, o que aponta para uma estreita relação entre escrita e imagem.

João Adolfo Hansen traz uma informação que mostra como, etimologicamente, escrita e pintura estavam em acordo desde a Antiguidade, visto que, "nos textos gregos o verbo graphein significa tanto escrever quanto pintar, assim como o substa ntivo graphé significa escrita e pintura" (HANSEN, 2006, p. 91). No século XIV, Leon Battista 
Alberti defendia a capacidade da imagem e da escrita de alcançarem objetivos semelhantes. Ao alegar que "os movimentos da alma são conhecidos pelos movimentos do corpo" (ALBERTI, 2014, p. 114), ele sustenta que a pintura, em uma representação do visível, pode representar por consequência, um estado da alma, e usa o exemplo do texto de Luciano de Samósata quando aponta a companhia dos poetas e oradores como um caminho para que o pintor seja bem-sucedido:

A companhia dos poetas e oradores traria aos pintores muita satisfação. Eles têm muitos recursos em comum com os pintores; dotados de vasto conhecimento sobre muitas coisas, serão de grande ajuda para uma bela composição da história, cujo maior mérito consiste na invenção que, como veremos, costuma ser de tal força que, mesmo sem a pintura, agrada por si mesma. Não se lê sem louvor a famosa descrição da Calúnia que Luciano diz ter sido pintada por Apeles. Penso que não é assunto fora do nosso propósito narrá-la aqui para lembrar aos pintores a que pontos da invenção devam eles estar atentos. Havia nessa pintura um homem com duas orelhas enormes, tendo junto a si, de um e outro lado, duas mulheres: uma se chamava Ignorância e a outra, Suspeita. De lugar pouco distante vinha a Calúnia. Era uma mulher de aspecto belíssimo, mas parecia, em sua fisionomia, astuta demais. Trazia na mão direita uma tocha acesa e, com a esquerda, arrastava pelos cabelos uma jovem que estendia as mãos para os céus. E havia também um homem pálido, feio, todo sujo, de má catadura, que se poderia comparar a uma pessoa que se tornara magra e queimada por longa labuta nos campos de batalha: era o guia da Calúnia e se chamava Despeito. Havia duas outras mulheres, companheiras da Calúnia, que lhe ajustavam os enfeites e as roupas; umas chamava-se Insídia, a outra, Fraude. Atrás delas estava a Penitência, trajando vestes fúnebres, a se dilacerar toda. Atrás desta vinha uma jovem recatada e pudica, chamada Verdade. Essa história, se contada, já agrada, imagine-se a graça e o encanto que teria se a víssemos pintada por Apeles. (ALBERTI, 2014, p. 129)

Alberti recomenda a atenção dos pintores à narrativa para a produção das pinturas. As personificações das abstrações apa recem com características físicas: a Calúnia é bela e a sua astúcia transparece em sua fisionomia. Além disso, há, associada a ela, os símbolos, o que vai a encontro do que defende Panofsky, sobre as alegorias serem comumente compostas por personificações e símbolos.

A recomendação de Alberti foi considerada e discutida nos anos posteriores, tamanha a sua importância. No século XV, o artista Sandro Botticelli seguiu o método ao usar motivos dessa mesma história de Luciano de Samósata citada em Alberti para pintar um quadro intitulado exa ta mente A Calúnia de Apeles ${ }^{1}$ (1494). O texto
1. La Calunnia di Apelle. 
de Sa mósa ta é um exemplo de écfrase, termo que, segundo Paulo Martins, foi empregado pioneiramente por um rétor entre o período de Augusto e a segunda sofística e que, embora não tenha marcado "o início de um uso pragmático, [...] a partir desse momento, falar de écfrase na Roma e na Grécia do período passa a ser algo corrente nas escolas de retórica" (MARTINS, 2016, p. 164-5). João Adolfo Hansen explica que, no período conhecido como segunda sofística, a écfrase era um "gênero de discurso epidítico" praticado, por oradores e filósofos, "como exercício de eloquiência ou declamação". A écfrase desse período pode ser definida, então, como "antigraphai ten graphein", que significa "contrafazer do pintado", porém com a particularidade de que as descrições são uma forma de "emulação verbal que compete com a pintura, descrevendo quadros inexistentes" (HANSEN, 2006, p. 86).

Já a realização das pinturas a partir de métodos retóricos recebe o nome de compositio. Segundo Élie Faure, Giotto foi o pioneiro dessa "introdução da ordem intelectual no caos das sensações" (FAURE, 1949, p. 80). Michael Baxandall explica a técnica:

Pois esta sua noção de compositio é uma metáfora bastante precisa, que transfere à pintura um modelo organizaciona proveniente da própria retórica. Compositio era um conceito técnico básico, que qualquer jovem aluno em uma escola humanística aprendia a aplicar na linguagem. Não equivale à nossa composição literária, referindo-se em vez disso à disposição de uma única e complexa sentença (ou período) a partir de uma estrutura hierárquica quaternária: palavras engendram frases, que compõem cláusulas, que culminam em períodos: fit a utem ex cuniunctone verborum comma, ex commate colon, ex colo periodos. (BAXANDALL, 2018, p. 151)

Giotto, em uma correspondência com a pintura, se pautava no método utilizado pelos oradores, que partia m das menores unidades (palavras) e as organizavam até as maiores (períodos).

Dessa forma, sendo o assunto pintura e escrita, surge o nome de Giotto. Vejamos agora como os trabalhos do pintor italia no foram recebidos, no início de século XX, em um uma obra de um romancista que ta mbém tendia a romper as fronteiras entre pintura e escrita. Trata-se de Marcel Proust, o francês a utor de Em Busca do Tempo perdido, obra permeada de écfrases. É importante destacar que, com o tempo, surgiram novas definições de écfrase, inclusive distintas daquela dos retores. Aleida Assmann define écfrase como "descrição literária da imagem que reinsere o medium imagético na escrita, mas de modo que a legibilidade desta permita abertura à sugestividade da imagem." (ASSMANN, 2018, p. 248). Como se 
2. "notional ekphrasis"

3. "actual ekphrasis"

4. (Tradução minha)

5. "There are two basic modes of both Notional ekphrasis involves a writer's creation and description of an imaginated work of art. [ ] Actual ekphrasis involves the evocation of an existing work of art." (KARPELES, 2008, p. 20-1). percebe na descrição de Hansen, o termo écfrase surge entre os retores como descrição de pinturas imaginadas, o que não consta na definição de Assmann. Eric Karpeles nomeia, define e exemplifica dois tipos, "écfrase conceitual" 2 e écfrase real': "Há dois tipos básicos de ekphrasis e Proust empregou os dois. A ekphrasis conceitual envolve a criação e descrição, pelo escritor, de uma obra de arte imaginada. [...] A ekphrasis real envolve a evocação de uma obra de arte existente." ${ }^{4}$ (KERPELES, 2008, p 20-1). ${ }^{5}$ Karpeles exemplifica a écfrase conceitual com o escudo de Aquiles por Homero, na Ilíada, e a écfrase rea com o poema de W. H. Auden, Musée de Beaux Arts, sobre a pintura de Brueghel. Ele afirma que a mbos os tipos de écfrase são utilizados por Marcel Proust em Em Busca do Tempo perdido, o que, de fato, procede. Conforme veremos no decorrer deste trabalho, o narrador proustiano, semelhante ao eu lírico do poema de W. H. Auden, nos evoca uma obra de arte existente, a saber, o afresco Caridade (1304-1306) pintado por Giotto na capela de Arena em Pádua. Porém, o narrador faz isso simulta neamente a uma outra écfrase: a da criada de cozinha que trabalha em sua casa, em Combray, que se torna uma obra de arte imaginária, assim como as da écfrase dos retores.

Os objetivos deste trabalho são: analisar a mbas as écfrases no romance No caminho de Swann, de Marcel Proust, a saber, a écfrase real a partir da Caridade de Giotto, e a écfrase conceitual, a partir da criada de cozinha e, em seguida, responder aos seguintes questionamentos: por que, dentre tantas alegorias de caridade, é mencionada no romance de Proust a de Giotto ? E por que a Caridade de Giotto se diferencia tanto das demais?

\section{CARIDADE DAS CARIDADES. TUDO É CARIDADE?}

Comecemos discutindo a relação de Marcel Proust com a pintura. A presença das pinturas em sua grande obra é sempre destacada, porém, a relação pintura-escrita teve início anteriormente ao seu processo criativo. Proust havia se dedicado à tradução dos textos do crítico de arte britânico John Ruskin, o que possibilitou a ele o conta to com descrições de pinturas, sobretudo as italia nas, que apa recem, posteriormente, em Em Busca do Tempo Perdido Beauthéc afirma que, para além das leituras, Proust realizou viagens para conhecer as imagens descritas nos livros de Ruskin : "Seu trabalho de tradução deu a Proust o desejo de ir aos lugares que seduzira m o crítico. [...] Ruskin propõe vá rios itinerá rios de acordo com o tempo de que o visitante dispõe" ${ }^{\prime \prime}$ BEAUTHÉC, 1997, p. 73). 7

Apesar de o autor ter ido ao encontro das imagens vistas nos livros, nem todas as pinturas descritas em seus romances foram, de fato, visitadas por Proust. Chernowitz
6. (Tradução minha)

7. "Son travail de traduction donne à Proust le désir d'aller sur les lieux qui ont séduit le critique. [...] Ruskin propose plusieurs itinéraires selon le temps dont dispose le visiteur" ( BEAUTHÉC, 1997, p. 73)

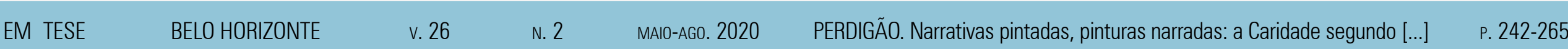

Teoria, Crítica Literária, outras Artes e Mídias 
10. (Tradução de Mário Quintana).

11. " D'ailleurs elle-même, la pauvre fille, engraissé par sa grossesse, jusqu'à la figure, jusqu'aux joues qui tombaient droites et carrées,ressemblait en effet assez à ces vierges, fortes et hommasses, matrones plutôt, dans lesquelles les vertus sont personnifiées à l'Arena. "

12. "DROUST, 1979,

13. "engraissé".

14. "fortes".

15. "engraissé par sa grossesse".
Isso confirma o que Karpeles bem defendeu, que, em sua obra, Proust utiliza dois tipos de écfrase.

Percebe-se que a primeira semelhança apontada entre a criada e a virtude de Giotto são as vestes - opalandas. A descrição da criada como doentia, grávida e entregue ao trabalho, embora seja comum à ideia de caridade de vários pintores - conforme veremos neste trabalho - não despertara m, em Marcel, a associação com a sua fotografia da Caridade de Giotto; somente as vestes é que ele identificou como semelhantes. A descrição continua:

Aliás ela própria, a pobre rapariga, gorda, com a gravidez, até o rosto, a té às faces que tombavam retas e quadradas, muito se assemelhava com efeito àquelas virgens, fortes e varonis, ou antes matronas, que na Arena personificam as virtudes. ${ }^{10}$ (PROUST,1979, p. 52) $)^{11}$

Pensando melhor, - o que se deduz do "aliás" 12 - Marcel encontra outra característica da criada que é comum não exclusiva e necessariamente à Caridade de Giotto, mas a todas as virtudes do pintor: o fato de a criada ser gorda. Porém, ele não usa o mesmo adjetivo para descrevê-las. Para a criada, gorda ${ }^{13}$; para as virtudes, fortes ${ }^{14}$. Além disso, ele menciona que a gordura da criada é decorrente da gravide ${ }^{15}$, o que muito a difere das virtudes de Pádua, que são virgens. Isso indica que a virgindade como característica das alegorias de Giotto vai contra a ideia de Marcel - e contra a ideia de muitos pintores, conforme veremos adiante- de uma caridade associada à maternidade. Essa associação, por Marcel, se deduz do fato de ele pensar na caridade em função de a criada estar grávida.

Adiante em sua descrição, Marcel justifica tanto a alegoria da caridade de Giotto quanto a criada de cozinha pelo símbolo. Mais uma vez, há uma referência à explanação de Panofsky sobre a alegoria ser composta por personificação e símbolos:

E reconheço agora que ainda se lhe assemelhavam de outra maneira essas Virtudes e Vícios de Pádua. Da mesma forma que a imagem daquela rapariga era acrescida pelo símbolo adicional que ela carregava adiante do ventre sem parecer compreender-lhe o sentido e sem que nada em seu rosto lhe traduzisse a beleza e o espírito, como se fora tão-somente o pesado fardo, é assim, sem o suspeitar, que a possante comadre que está representada na Arena debaixo do nome de "Caritas" (e cuja reprodução se achava pendurada à parede da minha sala de estudos em Combray) encarna a referida virtude sem que nenhum pensamento de caridade haja alguma vez passado pelo seu rosto enérgico e vulgar. ${ }^{16}$ (PROUST, 1979, p. 52-3) ${ }^{17}$
16. (Tradução de Mário Quintana).

17. "Et je me rends compte maintenant que ces Vertus et ces encore d'une autre manière. même que l'image de cette fille était accrue par le symbole ajouté qu'elle portait devant son ventre, sans avoir l'air d'en comprendre le sens, sans que rien dans son visage en traduisît la beauté et visage en traduisit la beaute et
l'esprit, comme un simple et pesant fardeau, de même c'est sans paraitre $s^{\prime}$ 'en douter que la puissante ménagère qui est représentée à l'Arena au-dessous du nom "Caritas " et dont la reproduction était accrochée au mur de ma sale d'études, à Combray, incarne cette vertu, c'est sans qu'aucune pensée de charité semble avoir jamais pu être exprimée par son visage énergique et vulgaire."(PROUST, 1979, p. 182-3)

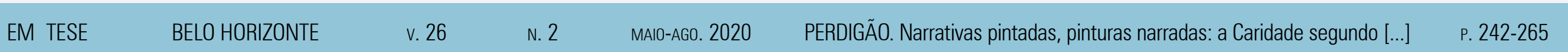


Marcel diz que entende ser a criada uma alegoria da caridade em função de portar um cesto, símbolo da servidão. Segundo a opinião do narrador proustiano, a criada e a alegoria de Giotto vão contra o que Alberti estabelece como necessário para que a imagem represente a alma uma vez que os traços do rosto não indicam caridade. Neste caso, sem os símbolos, a saber, as cestas, não haveria, de fato, a alegoria da caridade, visto que o rosto da criada não transparece o sentimento, assim como o rosto da virgem de Giotto, que é enérgico e vulgar, também não o faz.

Levando adiante essa questão das características físicas que representam a alma, veja mos como outros pintores fizeram suas alegorias de caridade, para averiguar se os rostos transparecem caridade e se há, além disso, símbolos que compõem as alegorias. Comecemos pelo século XIX, com a pintura Ciência e Caridade (1897) de Picasso. Caridade e Ciência estão dissociadas em duas alegorias, de modo que a Ciência cumpre a função de cuidar da enferma, porém sem demonstrar sentimentos, ao passo que a Caridade olha a paciente e tem nas mãos uma bebida aparentemente um chá. O chá é o símbolo que, junto à personificação, faz, da imagem, uma alegoria de caridade. Apesar da veste de convento, a Caridade de Picasso tem, no colo, uma criança bem próxima a ela. A proximidade da criança indica que ela sente, na mulher, uma tendência maternal; ou seja, mesmo ela não sendo uma mãe, e sim uma virgem religiosa, ela transpa rece algo de maternal que atrai a criança. Comparando a Caridade de Picasso com a de Giotto, percebe-se que aquela tem não só o símbolo da caridade nas mãos, mas uma atitude caridosa, visto que assiste uma doente, oferecendo-lhe algo para beber. A de Giotto, porém, apesar do símbolo da caridade na mão - um cesto com alimentos - não parece oferecer a comida a ninguém. A Caridade de Giotto seria, então, internamente mais próxima da Ciência de Picasso, visto que ela faz um serviço, porém não aparenta sofrer por aquele a quem serve.

Ainda no século XIX, temos a Caridade do Bouguereau. É assaz maternal, rodeada por crianças, as quais ela alimenta e sobre as quais ela mantém um olhar atento e preocupado. A a mamentação é considerada um ato de alimentação que inclui o amor, dessa forma, ela não só alimenta, mas transfere seu amor para os filhos através do leite. A Caridade de Bouguerau tem os tesouros aos pés, os quais ela usa para que uma das pernas fique mais confortável para acomodar uma das crianças em seu colo. A criança mais próxima dos tesouros olha na direção do leitor da imagem com certo medo e se coloca totalmente sobre as vestes da Caridade, que é quem tem a capacidade de protegê-la, em sua inofensividade. A criança 
18. (Tradução de Mário Quintana).

19. "Par une belle invention du peintre elle foule aux pieds les trésors de la terre, mais absolument comme si elle piétinait des raisins pour en extraire le us ou plutôt comme elle aurat monte sur des sacs pour se hausser ; et elle tend à Dieu son coeur enflamme, disons mieux, elle le lui " passe " comme une cuisinière passe un tire-bouchon par le soupirail de son sous-sol à quelqu'un qui le lui demande a fenêtre du rez-de-chaussée. PROUST, 1979, p. 183) à esquerda, na imagem, ao contrário da da direita, não está a medrontada; pelo contrário: parece distraída, o que pode significar, ta mbém, uma vulnerabilidade. Isso mostra que a Caridade protege a mbas, em seus diferentes perfis: a a medrontada e a distraída, a mbas inofensivas e vulneráveis. As diferenças mais evidentes entre a Caridade de Bouguereau e a de Giotto são: o fato de os tesouros, no caso da de Giotto, estarem aos pés da Caridade, em sacos a marrados, o que não nos dá a certeza de serem de fato tesouros. Além disso, a Caridade de Giotto, estando de pé, consegue alcançar Deus pisando nos sacos. Vejamos a impressão de Marcel sobre esse detalhe:

Por uma bela invenção do pintor, ela calca aos pés os tesouros da terra, mas exatamente como se pisasse uvas num lagar ou antes, como se tivesse subido em cima de uns sacos para elevar-se mais; e estende a Deus o seu coração inflamado, digamos melhor, ela o "passa" a Ele, como uma cozinheira passa um saca-rolhas, pelo respiradouro do seu subsolo, a alguém que lho pede da janela do andar térreo. ${ }^{18}$ (PROUST, 1979, p. 53) ${ }^{19}$

De fato, a Caridade de Giotto pode estar pisando nos tesouros por desprezo, estando ela acima deles, mas ta mbém pode ser que ela precise deles em seu processo de ascese, visto que, na imagem, são os tesouros que a permitem alcançar Deus. Há, também, uma possível interpretação de os tesouros da Terra simbolizarem os tesouros do Céu, se levarmos em conta a função da alegoria para os florentinos, contexto no qual Giotto estava inserido. Hansen explica:

A alegoria é instrumento para pôr a alma humana em estado de receptividade poética da unidade invisível. Sua ação termina, portanto, quando a alma entra em contato extático com aquilo que deseja que esteja além do movimento e da própria forma alegórica. O que pode significar, ainda, que a vida humana tem a estrutura metafórica de um sonho: qualquer coisa que exista no mundo inferior se encontra rá também no superior, mas em forma mais elevada; e qualquer coisa do mundo superior, por sua vez, poderá ser encontrada no inferior, mas em forma adulterada. O fogo, por exemplo, que arde materialmente no mundo inferior, é metáfora do fogo seráfico do Intelecto. (HANSEN, 2006, p. 176)

A explanação de Hansen me leva a considerar que os tesouros da terra podem ser representações, no mundo inferior, do que existe no mundo superior. Analoga mente, também o cesto na mão da Caridade poderia ser representação, no mundo inferior, da oferta a Deus, no mundo superior.

Convém nos determos nas especulações sobre a cesta de alimentos. Nas outras alegorias de caridade, alimentação e

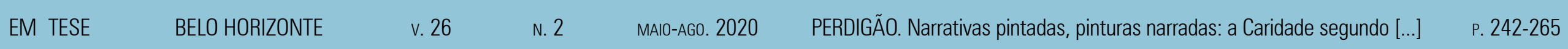

Teoria, Crítica Literária, outras Artes e Mídias 
o amor geralmente estão associados através da ama mentação. Aparece ta mbém nas pinturas intituladas Caridade de: Bouguereau (1878), Pollaioulo (1469), Cranach (15301540), Van Dyck (1633), Franceschini (1683-1684), Guido Reni (1606), Strozzi (1581) e na escultura de Tino de Camaino (1321). Considerando a amamentação como característica comum a tantas obras de arte alegóricas da caridade e sendo a amamentação um a to não só de alimentar, mas também de transmitir amor, a particularidade da obra de Giotto indica que, nela, amor e alimentação não estão juntos. A Caridade de Giotto tem em uma das mãos uma cesta de alimentos, porém, ela não os oferece a alguém especificamente, e o coração, por sua vez, está em outra mão, sendo oferecido não a crianças, não a pessoas que precisam dela, mas a Deus, de quem ela precisa. Ao colocar alimentos de um lado e coração do outro, Giotto desassocia amor e servidão. As ações para o mundo terreno e para o Céu estão separadas, ao passo que, nas obras de outros pintores, poderia ser inferido que as ações da Caridade com as crianças já garantiriam um vínculo com Deus, ou a construção de um reino celeste.

\section{CARIDADE SEM CARIDADE}

\section{OU CARIDADE SEM AMOR?}

Cada qual com suas particularidades, mesmo que algumas tenham algo que remeta à de Giotto, nenhuma das pinturas da Caridade citadas na seção anterior está desacompanhada de alguma criança, de modo que todas criam uma ideia de maternidade. Além disso, a maioria delas está a mamentando ou prestes a a mamentar e não tem o olhar erguido, mas na direção dos que dela precisam. A maioria delas poderia corresponder à imagem da Caridade com caridade que o narrador proustiano tinha em sua mente. Retomemos a pergunta que objetivamos responder neste trabalho: havendo tantas outras alegorias que, de fato, se assemelhavam mais à ideia de caridade, ou seja, a uma Caridade com caridade, por que Swann associa a criada logo à Caridade sem caridade?

É importante considerar que Marcel diz que foi Swann quem chamou a atenção dele para a semelhança entre a criada e a Caridade de Giotto. Paul de Man defende que o narrador tem uma interpretação mais profunda das semelhanças entre as duas alegorias, a saber, a humana e a do afresco italiano:

Marcel, que tem uma mente mais literária (ou seja, retoricamente menos ingênua) do que Swann, observou que a ajudante de cozinha e a Caridade de Giotto são semelhantes entre s em mais outro aspecto além da forma física. Sua semelhança ta mbém tem uma dimensão ligada à leitura e ao entendimento, e nesse aspecto a semelhança é curiosa mente negativa. A

EM TESE BELO HORIZONTE $\quad$ v. $26 \quad$ N. $2 \quad$ MAIO-A60. $2020 \quad$ PERDIGÃO. Narrativas pintadas, pinturas narradas: a Caridade segundo [...] $\quad$ P. 242-265

Teoria, Crítica Literária, outras Artes e Mídias 
propriedade partilhada entre a ajudante e a Caridade é a do não entendimento: ambas se destacam por traços que exibem "sem que pareçam entender o seu significado". Ambas parecem condenadas à mesma dislexia. (DE MAN, 1996, p. 92)

A leitura de Paul de Man é que o pequeno Marcel percebe que o fato de a Caridade de Giotto carregar um cesto com alimento não significa, necessariamente, que há um entendimento, por parte daquela figura, de que ela é uma personificação associada a um símbolo caridade, o que constitui uma alegoria. Da mesma forma, a criada não entende que ela também, portando o cesto na mão, carrega um símbolo de caridade e que suas características físicas são aquelas que os pintores e escultores utilizam para que a pintura represente fisicamente uma alma caridosa. Assim, a semelhança não é apenas física; algo mais a criada compartilha com a Caridade de Giotto: o fato de, ao invés de olhar para quem está abaixo de si, olhar para quem está acima, no caso, a chefe da cozinha, Françoise. As Caridades de outros pintores têm uma servidão a, possivelmente, seus filhos, seres para os quais elas devotam amor; a de Giotto, assim como a criada, não tem, por perto, ninguém a quem se ligue por vínculos afetivos. O próprio Marcel destaca que as criadas são sempre substituídas, ou seja, não permanecem na casa tempo suficiente para criarem vínculos. Por mais que De Man defenda que é disléxica a leitura que a criada faz do símbolo que carrega, devo refutar que ela faz uma leitura perfeita de que, na alegoria na qual ela está inserida, faltam as criaturas amadas. Ela percebe a sua efemeridade em meio àquela família, sabe que está ali apenas de passagem.

Paul de Man prossegue sua interpretação:

A ajudante de cozinha se assemelha à Caridade de Giotto, mas parece que o gesto desta também a faz parecida com Fra nçoise. A primeira semelhança não é de todo improvável: os sofrimentos da infeliz moça são evocados com intensidade suficiente para inspirar um sentimento que pensa que poderia facilmente se confundir com caridade. Mas a segunda semelhança, com Françoise, é mais difícil de entender: se a imagem, como representação, ta mbém conota Françoise, ela se desvia muito de seu objetivo, pois nada poderia ser menos caridoso que Françoise, especialmente em sua atitude para com a ajudante da cozinha. [...] um único ícone engendra dois significados, um representacional e literal, e o outro alegórico e "próprio", e que os dois significados lutam um contra o outro com a força cega da estupidez. Com a cumplicidade do escritor, o significado literal apaga o alegórico. (DE MAN, 1996, p. 94). 
A explicação de De Man é de que o sofrimento da criada remete o narrador proustiano à caridade; não à de Giotto mas à ideia comum de caridade. Já a semelhança entre a criada e a fria Françoise vem a ser o sentido literal da criada, não alegórico. Sendo assim, se o leitor consegue captar que, embora a maternidade, a corpulência, a servidão e a cesta com alimentos sejam símbolos que remetem à caridade, a criada, na verdade, não é caridosa, por conseguinte, o leitor vai descartar a alegoria e associá-la apenas à literalidade, que é uma mulher sem caridade. Porém, devo discordar novamente de De Man: o fato de a criada se afastar da ideia comum de caridade não indica que ela não seja alegórica. Como vimos, a Caridade de Giotto pouco se assemelha à ideia comum que se tem da virtude, porém não deixa de ser alegórica; o mesmo se aplica à criada. A já discutida inexistência de laços entre ela e outros seres ao seu redor, ou seja, a inexistência de crianças que dela dependam, já remete à figura feminina pintada por Giotto a qual olha pra cima, não pra quem precisa dela, mas para aquele de quem ela precisa - Deus - e a Ele passa o coração. A criada, também, olha para Françoise, a quem deve obediência, e chega a se assemelhar a ela na frieza.

Bagolini apresenta uma explicação para a existência de lugares-comuns na compositio, método empregado por Giotto:
A representação necessita, ao se tratar da escrita, da sentença para estruturar a enunciação, assim como no caso da pintura, do desenho para estruturar o colorido. A conveniência entre as partes é necessária e aconselhável, para pôr diante dos olhos da mente do espectador ou leitor tal representação, porquanto o que a torna perfeita é sua equivalência com aquela imagem conhecida previamente e armazenada na memória de seus destinatários, a sinonímia. [...] O De Pictura de Alberti atesta a utilização destes preceitos em sua composição, não divergindo quanto à escolha de lugares-comuns de outros discursos que lhe são contemporâneos ou anteriores (BAGOLINI, 2018, p. 18).

Bagolini explica o fato de Giotto ter utilizado elementos que remetem à imagem que o leitor já tem da caridade, a saber, o alimento e o corpo forte. São esses os lugares-comuns de outros discursos e outras pinturas dessa virtude, inclusive que, como vimos, foram muito utilizados mesmo posteriormente a ele. Porém, Giotto insere, em seu trabalho, elementos que não são, usualmente, associados à caridade. Como já disse, assim como a alegoria de Giotto, a de Proust não tem todos os símbolos usuais da sua alegoria, mas não deixa de ter os lugares-comuns: o cesto, a servidão, a corpulência. Paul de Man alega que foram essas características que Swann percebeu e que Marcel, sendo mais literário, percebeu outras. Todavia,

EM TESE BELO HORIZONTE $\quad$ v. $26 \quad$ N. 2 MAIO-AGO. 2020 PERDIGÃO. Narrativas pintadas, pinturas narradas: a Caridade segundo [...] $\quad$ P. 242-265

Teoria, Crítica Literária, outras Artes e Mídias 


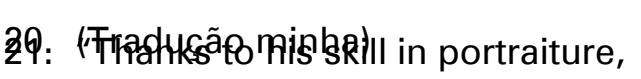
this realism departs from the representation of conventiona faces and for the sake of physiognomic truth admits even commonness and vulgarity of features" (CHERNOWITZ, 1945, p. $68)$. tendo a pensar que se fosse apenas pelas semelhanças físicas, Swann poderia ter feito a comparação com outras alegorias de caridade. Creio que a escolha da de Giotto significa que o próprio Swann já fez a leitura de que o afresco de Pádua era o que mais se assemelhava à criada dos amigos.

Chernowitz destaca a vulgaridade das características e mesmo o fato de as figuras de Giotto serem comuns, o que está de acordo com a minha hipótese de que, ao contrário do que afirma De Man, Swann não viu apenas uma semelhança física entre a Caridade de Giotto e a criada uma vez que as características físicas do afresco poderiam ter sido encontradas em qualquer outro ser: "Graças à sua habilidade de fazer retratos, esse realismo [de Giotto] parte da representação de rostos convencionais e, por causa da verdade fisionômica, admite inclusive características vulgares e comuns"20 (CHERNOWITZ, 1945, p. 68) ${ }^{21}$.

Saindo da ficção para melhor argumentar, o primeiro contato de Marcel Proust com a alegoria de Giotto foi a descrição de Ruskin, na qual o crítico comete uma confusão:

Ruskin descreve a Caridade segurando, na mão esquerda, um objeto que se assemelha a um coração: primeiro ele supõe que a cena representa Deus oferecendo seu próprio coração caridoso a ela, mas se corrige numa nota posterior: "não há dúvida de que me equivoquei na leitura dessa ação: ela dá seu coração a Deus, enquanto faz oferendas à humanidade." Ruskin ta mbém discute a retórica a mbivalente do pintor, que é, diz ele, "muito literal em [seu] significado e igualmente figurativa.” (DE MAN, 1996, p. 93-4).

A confusão de Ruskin pode ter chamado a atenção de Proust, como leitor, para o coração nas mãos da Caridade de Giotto. De tantas alegorias citadas neste trabalho, apenas a de Pollaioulo tem em comum com a de Giotto um coração nas mãos, porém, não tão evidente quanto o de Pádua, o que indica que o coração não é comumente símbolo associado a personificações de caridade. A confusão do crítico tem a ver já com a ideia de que, geralmente, quem doa é quem menos precisa e quem recebe é quem mais precisa, conforme se dá em todas as outras alegorias aqui mencionadas. Isso o levou a pensar, a princípio, que a Caridade de Giotto recebe de Deus o coração, mas depois ele percebe o engano. Ruskin diz que a alegoria do italiano é, ao mesmo tempo, muito literal e figurativa. A questão figurativa está nos luga res-comuns que ele emprega, a saber, as características físicas da figura e a cesta com alimentos. A literalidade, a meu ver, está no que Marcel observou, de as pessoas ditas caridosas serem

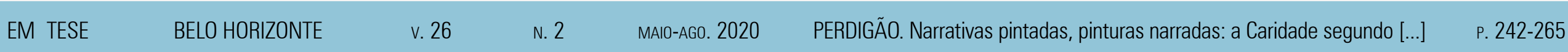

Teoria, Crítica Literária, outras Artes e Mídias 
22. (Tradução de Mário Quintana).

23. "Quand, plus tard, j'ai eu 'occasion de rencontrer, au cours de ma vie, dans des couvents par exemple, des incarnations vraiment saintes de la charité active, elles avaien généralement un air allègre, positif, indifférent et brusque de chirurgien pressé, ce visage où ne se lit aucune commisération, aucun attendrissement devant la soufrance humaine, aucune crainte de la heurter, et qui est visage sans douceur, le visage bonté. (PROUST, 1979, P. 184) indiferentes àquelas que sofrem. O narrador exemplificou com as irmãs dos conventos:

Quando tive mais tarde ocasião de encontrar, no curso da vida, em conventos, por exemplo, encarnações verdadeiramente santas da caridade ativa, tinha meralmente um ar alegre, positivo, indiferente e brusco de cirurgião apressado, essa fisionomia em que não se lê nenhuma comiseração, nenhum enternecimento diante da dor humana, nenhum temor de feri-la, e que é a fisionomia sem doçura, a fisionomia antipática e sublime da verdadeira bondade. ${ }^{22}$ (PROUST, 1979, p. 53) ${ }^{23}$

Proust ressalta que as mulheres que estavam associadas à caridade, a saber, as virgens dos conventos, apresentavam a mesma antipatia e indiferença da Caridade de Giotto. Sendo assim, ela seria realista por representar as pessoas consideradas caridosas, que estão nos conventos e que se dedicam a tratar enfermos, porém sem se deixarem atingir pela dor daqueles que trata $\mathrm{m}$. Retomando Ciência e Caridade de Picasso, as irmãs do convento, assim como a Caridade de Giotto, seriam como a Ciência da pintura.

A percepção, por Proust, da realidade em Giotto também pode ter sido em decorrência de sua leitura de Ruskin, que mais de uma vez discorreu sobre isso:
Cuidadosa imitação da natureza. Nesse princípio está a grande força de Giotto e todo o segredo da revolução que ele efetuou. [...] Ele se tornou grandioso, o mestre dos grandiosos, simplesmente tendo interesse pelo que estava acontecendo ao seu redor; substituindo os gestos dos homens vivos por atitudes convencionais, retratos de homens vivos por rostos convencionais, e incidentes da vida cotidiana por circunstâncias convencionais. (RUSKIN, p. 18) ${ }^{24}$

A leitura de Ruskin pode ter chamado a atenção de Proust, mesmo antes de ter contato com a imagem, para todas as outras particularidades da Caridade de Giotto, a saber, a feição sem aparente sofrimento; a presença do coração como símbolo do a mor e dissociado do alimento; a ausência de crianças; o olhar erguido e os pés sobre os sacos fechados. Chega, então, o momento de finalmente responder ao segundo questionamento proposto neste trabalho: por que a Caridade de Giotto se diferencia tanto das de outros artistas? As particularidades da alegoria do italia no se explica m por ela ter sido produzida por compositio: "muito bons críticos a firmaram que ele [Giotto] era capaz de pintar aquilo que poetas representava m em palavras." (VILLANI apud BAXANDALL, 2018, p. 84). Em seu afresco, Giotto, de fato, pinta o que um poeta representou em palavras, a saber, o poeta Dante Alighieri. Para comprovar isso,
24. "Close imitation of nature. In this one principle lay Giotto's great strenght, and the entire secret of the revolution he effected[..]lt was simply by being interested in what was going on around him by substituting the gestures of living men for conventional attitudes, and portraits of living men for conventional faces, and incidents circumstances, that he became great and the master of the great. (RUSKIN, p. 18)
EM TESE BELO HORIZONTE $\quad$ v. $26 \quad$ N. 2 MAIO-AGo. 2020 PERDIGÃO. Narrativas pintadas, pinturas narradas: a Caridade segundo [...] $\quad$ P. 242-265

Teoria, Crítica Literária, outras Artes e Mídias 
25. (Tradução de Décio Pignatari).

26. “D'allora innanzi, dico che Amore segnoreggiò la mia anima, la quale fu sì tosto a'llui disponsata, e comincio a prendere sopra signoria per la virtì che dava la mia ymaginatione, me la mia ymaghatione, che piaceri compiutamente. Elli mi comandava molte volte che io cercassi per vedere questa angiola giovanissima" (ALIGHIERI, 1999, p. 65) passemos à leitura de alguns excertos de Vida Nova, de sua autoria.

Os exemplos de pinturas alegóricas que citei mostram que a servidão comumente era associada à caridade, visto que em todas as alegorias havia uma figura feminina como serva de crianças. No texto de Alighieri, a servidão também aparece, porém na figura do narrador, que se coloca como servo do Amor:

Daí em diante, o Amor tomou conta de minha alma, que logo se dispôs a desposá-lo: em relação a mim, foi ganhando tanta firmeza e poderio, pela virtude que lhe transmitia a minha imaginação, que nada mais me restava senão atender aos seu menores desejos. Ordenava-me, muitas vezes, que eu fosse ver aquela menina-anja. ${ }^{25}$ (ALIGHIERI, 2001, p. 22) ${ }^{26}$

A menina-anja à qual ele se refere é Beatriz, sua a mada o Amor - com a letra inicial maiúscula - é uma personificação do sentimento que aparece nos sonhos de Dante. Em sua primeira aparição, ele está de posse do seu coração

No meu quarto, julguei ver uma névoa cor de fogo, em meio à qual discerni a figura de um senhor de aspecto amedrontador a quem o visse, mas que, no entanto, coisa extraordinária, dava demonstrações de uma alegria interna; muitas coisas dizia com suas palavras, das quais eu entendia apenas algumas poucas entre elas, as seguintes: "Eu sou o seu senhor". Parecia trazer nos braços uma pessoa nua, adormecida, envolta num pano levemente sanguíneo. Olhando atenta mente, reconheci nela a moça da saudação. Aquela que se dignara cumprimentar-me no dia anterior. Numa das mãos, parecia apertar uma coisa que ardesse em fogo e eu julguei escutar estas palavras: "Olhe seu coração."

Enqua nto o vulto se detinha, parecia despertar aquela que dormia e tanto se empenhava nisso que a fazia comer da coisa que ardia em suas mãos - e ela o comia, como que amedrontada. Mas não se passou muito e a alegria do vulto se converteu em choro amargo: chorando, afastou-se com a mulher nos braços, parecendo-me que ao céu se dirigiam..$^{27}$ (ALIGHIERI, 2001, p. 22-3) ${ }^{28}$

O trecho acima mostra que o Amor se coloca como senhor do narrador-personagem e, ta mbém, como alguém próximo de Beatriz, visto que ele a segura e a faz comer o coração. O Amor tem, então, o papel de servir o coração como alimento a outra pessoa. Quando a mulher, Beatriz, se alimenta do coração de Dante, o Amor assume seu ápice, que corresponde, ta mbém, à tra nsformação da sua alegria em choro. Isso ta mbém prepara Dante para chegar ao Céu, visto que, no catolicismo, a mor e sofrimento estão atrelados e fazem parte da jornada de
27. (Tradução de Décio Pignatari).

28. "Che mi parea vedere nella mia camera una nebula di colore di fuoco, dentro alla quale io discernea una figura uno signore, di pauroso aspecto a chi la guardasse; e pareami

con tanta letitia quanto a'ssé,

che mirabile cosa era; e nelle sue parole dicea molte cose, le quali io non intendea se non poche, tra le quali io intendea queste: "Ego Dominus tuus». Nelle sue braccia mi parea vedere una involta mi parea in uno drappo sanguigno leggieramente; la quale io riguardando molto intentivamente, conobbi ch'era la donna della salute, la quale m'avea lo giorno dinanzi degnato di salutare. E nell'una delle mani mi parea che questi tenesse una cosa la quale ardesse tutta; $e$ pareami che mi dicesse queste parole: «Vide cor tuum!!. E uando elli era stato alquanto, pareami che disvegliasse questa che dormia; e tanto si sforzava per suo ingegno, che le facea mangiare questa cosa che in mano li ardea, la quale ella mangiava dubitosamente. Apresso ciò poco dimorava che la sua letitia si convertia in amarissimo pianto; e così piangendo $\mathrm{si}$ ricogliea questa donna nelle sue braccia, e con essa mi parea (ALIGHIERI, 1999, p. 67)
(A) si ne gisse vero lo
EM TESE BELO HORIZONTE $\quad$ v. $26 \quad$ N. 2 MAIO-AG0. 2020 PERDIGÃO. Narrativas pintadas, pinturas narradas: a Caridade segundo [...] $\quad$ P. 242-265 
29. "elle le lui « passe " comme une cuisinière passe un tire-bouchon par le soupirail de son sous-sol à quelqu' un qui le lui demande à la fenêtre du rez-de-chaussée (PROUST, 1979, p. 183) santificação do homem. Caso o seu amor por Beatriz se efetivasse, o que significaria efetivar suas tristezas, ele estaria em ascese rumo ao Céu. Dessa forma, a amada é um meio de santificação e o Amor é um intermediário entre Dante e a mulher. Se Bea triz, virgem, estava indo ao Céu com o coração de Dante, ela estava de posse do coração e o entregaria a Deus. Uma mulher virgem, portadora do coração, e que o entrega a Deus nos lembra de uma figura: é exatamente como Giotto retratou sua Caridade.

Na leitura de Vida Nova, Beatriz de Dante não aparece com ares de sofrimento, o que fica reservado ao homem apaixonado e mesmo à alegoria do Amor. Se a Caridade de Giotto representa a amada de Dante, ela não é serva e não sofre: a servidão fica restrita a Dante, e o sofrimento, a Dante e ao Amor. Como Dante é o dono do coração e não Beatriz, ela simplesmente o entrega a Deus. Da mesma forma, a Caridade de Giotto simplesmente entrega a Deus o coração, nos dizeres de Proust, "como uma cozinheira passa um saca-rolhas, pelo respiradouro do seu subsolo, a alguém que lho pede da janela do andar térreo." (PROUST, 1979, p. 53) ${ }^{29}$.

Para melhor compreensão, vejamos outra aparição do Amor em Vida Nova:
Senti que o Amor me chamava, dizendo estas palavras: "Venho da parte daquela dama que foi o seu escudo e sei que o seu regresso não se dará tão cedo: por isso, o coração, que um dia deixei com ela, está comigo outra vez, para que outra cuide dele, como a primeira." ${ }^{30}$ (ALIGHIERI, 2001, p. 28)

O Amor deixa claro que a amada de Dante é quem tem a função de guardar e cuidar do coração. Na ausência de Beatriz, o Amor passará o coração à próxima mulher, que desempenhará a função de levá-lo a Deus. Dessa forma, em Vida Nova, Dante sofre e é o servo do Amor, enquanto a sua a mada come o seu coração e tem a missão de entregá-lo a Deus, mas não é apresentada como serva e nem como alguém que sofre. Isso explica a falta de servidão e de sofrimento nas feições da Caridade de Giotto. Além disso, Bea triz é indiferente às coisas da Terra, visto que está aqui apenas de passagem, para levar outros a Deus; por isso a posição da virtude de Giotto sobre os tesouros da Terra que, na verdade, são sacos que nem foram abertos. A Caridade é indiferente às riquezas; sequer tem curiosidade por elas, mantendo-as fechadas e usando-as apenas como algo necessário para cumprir sua função. Explico: como o objetivo de Beatriz é auxiliar alguém da Terra, e sendo também ela uma criatura humana, ela faz uso do que há neste mundo apenas para cumprir sua breve passagem e sua missão de levar a Deus o coração de um homem. Dante
30. (Tradução de Décio Pignatari).

31. "A me parve che Amore mi chiamasse e dicessemi queste parole: «lo vegno da quella donna la quale è stata tua lunga difesa, e so che lo suo rivenire non sarà. E però quello cuore ch'io ti facea avere a-llei, io l'ò meco, e portolo a donna la quale sarà tua difensione, come questa era". (ALIGHIERI, 1999, p. 76-7)

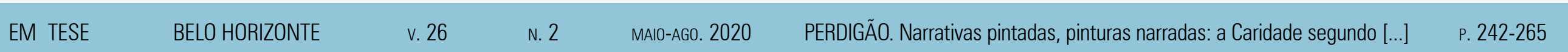

Teoria, Crítica Literária, outras Artes e Mídias 
chama o Amor de Senhor e o obedece, mas, em relação a Beatriz, o Amor não é um senhor, mas alguém que está junto a ela, que trabalha lhe entregando o coração para que ela o destine a Deus. Da mesma forma, a Caridade de Giotto não é escrava do Amor, como as outras que sofrem, escravizadas pelo amor que têm pelas crianças; ela simplesmente acaba de receber, do Amor, um coração, e o passa adiante. Para citar a associação do narrador de Proust, também as virgens do convento não sofrem, elas assistem aquele que sofre e dizem que vão conduzi-lo, em sua ascese, para que seu coração chegue a Deus.

\section{UM OLHAR PARA A INVEJA E...}

\section{EIS A CARIDADE DA CARIDADE}

No início do texto, foi apresentada a compositio como uma forma de pintura que remete à escrita. Baxandall explana que Giotto utilizava deste método, e que sua pintura parte do mesmo princípio da retórica, de que "palavras engendram frases, que compõem cláusulas, que culminam em períodos" (BAXANDALL, 2018, p. 151). Andre Chastel ta mbém a firma que "A arte de Giotto é toda em recorte e organização” (CHASTEL, 1991, p. 170). Sabendo que a Caridade de Giotto está na capela Arena, em Pádua, e que é parte de um trabalho maior, denominado Vícios e Virtudes, devemos considerar que, sendo uma obra de Giotto pela compositio, baseado nesse princípio retórico, a interpretação da Caridade não pode se restringir a um olhar para apenas uma das alegorias. Ciente disso, Swann deu, a Marcel, não só a imagem do afresco da Caridade, mas também de outros. Dessa forma, Marcel fez, em sua sala de estudos, algo semelhante a Giotto: recorte e orga nização. Em sua organização, Inveja e Caridade estão lado a lado, da mesma forma que estão, originalmente na Itália: "Como uma típica representação de psicomaquia, a Virtude da Caridade na Capela de Arena está oposta ao Vício Inveja”32 (JOHNSON, 1973, p. 174) ${ }^{33}$.

Veja mos como o na rrador proustiano descreve o outro afresco:

A Inveja, essa, já tinha mais expressão de inveja. Mas também nesse afresco, o símbolo ocupa tanto espaço e é representado como tão real, tão grossa é a serpente que silva nos lábios da Inveja, tão completamente lhe enche a boca escancarada, que os músculos do seu rosto estão distendidos pelo esforço de contê-la, como os de uma criança a soprar um balão, e a atenção da Inveja - e a nossa igualmente - concentrada de todo na ação de seus lábios, quase que não tem tempo de entregar-se a pensamento de inveja.

Apesar de toda a admiração do sr. Swann por essas figuras de Giotto, por muito tempo não senti nenhum prazer em
32. (Tradução minha).

33. "As in typical psychomachy representation, opposite the Virtue Charity in the Arena Chapel stand the Vice Envy" (JOHNSON, 1973,

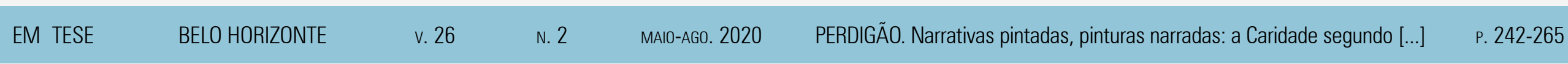

Teoria, Crítica Literária, outras Artes e Mídias 
34. (Tradução de Mário Quintana).

35. " L'Envie, elle, aurait eu davantage une certaine expression d'envie. Mais dans cette fresquelà encore, le symbole tient tant de place et est représenté comme si réel, le serpent qui siffle aux lèvres de l'Envie est si gros, il lui remplit si complètement sa bouche grande ouverte, que les muscles de sa figure sont distendus pour pouvoir le conternir, comme ceux dun enfant qui gonte un ballon de l'Envie - et la nôtre du même coup - tout entière concentrée sur I'action de ses lèvres, n'a guère de temps à donner à d'envieuses

6.Malgré toute l'admiration que M. Swann
profeses professait pour ces figures de Giotto, je n'eus longtemps aucun plaisir à considererer dans notre salle d'études, où on avait accroche les copies qu'il m'en avait rapportées, cette Charité sans charité, cette Envie qui avait l'air d'une planche illustrant seulement dan un livre de médecine la compression de de la langue ou par l'introduction de l'instrument de l'opérateur, une Justice, dont le visage grisâtre et mesquinement régulier était celui-là même qui, à Combray, caractérisait certaines jolies bourgeoises pieuses et sèches que je voyais à la messe et dont plusieurs étaien enrôlées d'avance dans les milices de réserve de l'Injustice. » (PROUST, 1979, p. 183) contemplar em nossa sala de estudo, onde haviam pendurado as cópias que ele me trouxera, aquela Caridade sem caridade, aquela Inveja que mais parecia uma ilustração de livro de medicina para mostrar a compressão da glote ou da companhia por um tumor da língua ou pela introdução do instrumento opera tório, uma Justiça cujo rosto comum e mesquinhamente regular era aquele mesmo que, em Combray, caracterizava certas boas burguesas devotas e secas que eu via na igreja e várias das quais já estavam engajadas na milícia de reserva da Injustiça. ${ }^{34}$ (PROUST, 1979, p. 53) ${ }^{35}$

Marcel alega ter identificado, na Inveja de Giotto, uma expressão de inveja, mas critica o excesso de espaço do símbolo, que causa, na personificação, um desconforto muscular, uma dificuldade de conter a serpente. Estando a Caridade próxima à Inveja, a serpente, difícil de conter, pode estar se movimenta ndo rumo à virtude vizinha. Disso, pode-se entender que há algo de invejável na Caridade sem caridade, algo que desperta o desejo da Inveja a ponto de lhe causar dor. Inclusive, a Inveja de Giotto remete o narrador proustiano a uma imagem de um livro de Medicina, tamanha a ideia de enfermidade e dor que ela transparece.

Marcel, após a Inveja, enxerga a Justiça que, assim como a Caridade, tem algo realista: remete a ele as burguesas religiosas. Ambas as virtudes citadas, Caridade e Justiça, não coincidentemente lembram Marcel de pessoas religiosas, porém pouco virtuosas. Todavia, a partir de certo momento de sua reflexão, o narrador consegue enxergar algo positivo nas virtudes de Pádua:

Com a pobre criada de cozinha, também não era a atenção incessante atraída para o seu ventre, pelo peso que o distendia? $\mathrm{E}$ assim também, muitas vezes o pensa mento dos agonizantes é desviado para o lado a fetivo, doloroso, obscuro, visceral, para esse avesso da morte que é justa mente o lado que ela thes apresenta, que lhe faz rudemente sentir e que muito mais se parece com um fardo que os esmaga, com uma dificuldade de respirar, com uma necessidade de beber, do que com aquilo a que chama mos ideias de morte.

Aqueles Vícios e Virtudes de Pádua deviam ter mesmo muita realidade, visto que me apareciam tão vivos como a criada grávida; e ela própria não se me afigurava menos alegórica. $E$ talvez essa não participação (pelo menos aparente) da alma de um ser na virtude que age por seu intermédio, tenha também, independente de seu valor estético, uma realidade senão psicológica, ao menos fisiognomônica, como se diz..$^{37}$ (PROUST, 1979, p. 53) ${ }^{38}$

A mudança de discurso de Marcel ocorreu após ter visto a Inveja e ter percebido o quão relevante era o
37. (Tradução de Mário Quintana).

38. "Chez la pauvre fille de cuisine, elle aussi, I'attention n'était-elle pas sans cesse ramenée a son ventre par le poids qui le tirait; et de même encore, bien souvent la vensee des agonisants est tourne obscur, viscéral, vers cet envers de la mort qui est précisém le lấć qu'elle leur présente, qu'elle leur fait rudement sentir et qui ressemble beaucoup plus à un fardeau qui les écrase, à une difficulté de respirer, à un besoin de boire, qu'à ce que nous appelons l'idée de la mort.

39. II fallait que ces Vertus et ces Vices de Padoue eussent en eux bien de la réalité puisqu'ils m'apparaissaient comme aussi vivants que la servante enceinte, et qu'elle-même ne me semblait pas beaucoup moins allégorique. Et peut-être cette non-participation (du moins apparente) de l'âme d'un être à la vertu qui agit par lui, a aussi en dehors de sa valeur esthétique une réalité sinon psychologique, au moins, comme on dit, physiognomonique. " (PROUST, 1979, p. 184)

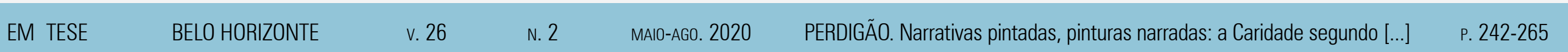


símbolo na composição da alegoria. Como já discutido, a Caridade de Giotto não é repleta de símbolos próprios de caridade, mas há alguns luga res-comuns. Ao perceber que a serpente, como símbolo que compõe a alegoria da inveja, era algo chamativo, Marcel, por comparação, conseguiu perceber que havia algo de chamativo também na Caridade que atraía o símbolo principal da Inveja e concluiu que, no caso, era o símbolo principal da alegoria Caridade: o ventre pesado que marcava o lugar-comum da servidão, da dedicação, do sofrimento, da doação. Com isso, ele encontrou a caridade da Caridade de Giotto. Ele já cogita que a não participação da alma da criada na virtude que ela representa pode ser apenas algo aparente. Anteriormente, o narrador tinha focado seu olhar apenas no símbolo do cesto, que era algo que a criada carregava para servir sua família, com quem ela não tinha, de fato, nenhum vínculo afetivo. Por isso parecia a Marcel que a criada era disléxica por carregar um símbolo de caridade e não o compreender. Porém, tempos depois, o narrador percebe que o símbolo da caridade por excelência era não o cesto, mas o ventre, no qual ela carregava alguém que precisava dela, que ela alimentava, nutria e a mava, assim como qualquer outra alegoria de caridade. O próprio narrador reconhece a importância dos símbolos na sua mudança de visão das alegorias de Giotto:
Mais tarde, porém, compreendi que a estranheza impressionante, a beleza especial daqueles afrescos, provinha do considerável lugar que ali ocupava o símbolo, e o fato de estar ele representado, não como um símbolo, pois o pensamento simbolizado não se achava expresso, mas sim como real, como efetivamente sofrido ou materialmente manejado, dava à significação da obra qualquer coisa de mais literal e preciso, e ao seu ensinamento qualquer coisa de mais concreto e incisivo. ${ }^{40}$ (PROUST, 1979, p. 53) (1 $^{4}$

\section{De Man apresenta sua explanação:}

As figuras precisam ser dotadas de uma intensidade semântica que lhes confira uma função representacional particularmente eficaz. O ícone alegórico precisa a trair a atenção; sua importância semântica deve ser dramatizada [...]A expressão facial da "pesada e máscula" matrona pintada por Giotto não conota nada de caritativa; e mesmo quando como no caso da Inveja, talvez pudéssemos detectar uma semelhança entre a ideia e o rosto da Inveja, a ênfase recai sobre um detalhe icônico que desvia nossa atenção e esconde de nossos olhos a semelhança potencial. (DE MAN,1996, p. 92-3)

A caridade da Caridade de Giotto foi encontrada no símbolo, após Marcel perceber que a inveja da Inveja era evidente pelo destaque do símbolo. A organização
40. (Tradução de Mário Quintana).

41. " Mais plus tard j'ai compris que l'étrangeté saisissante, la tenait à la grande place que le symbole y occupait, et que le fait qu'il fût représenté non comme un symbole puisque la pensée symbolisée n'était pas exprimée, mais comme réel, comme effectivement subi ou matériellement manié, donnait à la signification de l'oeuvre quelque chose de plus littéral et de plus précis, à son enseignement quelque chose de plus concret
et de plus frappant ". (PROUST 1979, p. 183-4)

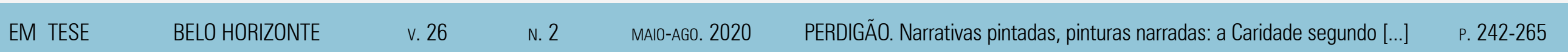

Teoria, Crítica Literária, outras Artes e Mídias 
das fotos em seu quarto, em semelhança à posição dos afrescos na capela de Arena, permitiu que o símbolo da Inveja fosse atraído por algo da virtude, o que levou a pensar que havia algo na Caridade que a Inveja não poderia ter; a saber, a sincera caridade concretizada na gestação. Assim, Marcel descobriu que a realidade de Giotto estava, sim, nos rostos comuns que permitiram a ele encontrar correspondência com as religiosas não caridosas e frias que ele já conheceu, mas, ta mbém, havia uma caridade real. Da mesma forma, a aparente falta de caridade da sua criada, com feições frias, se devia à a usência de vínculo afetivo com a família, decorrente da capacidade que ela teve de perceber que era temporária e substituível. Mas, ao se atentar a seu ventre pesado, Marcel pôde perceber que havia caridade naquele gesto. $\mathrm{O}$ ventre pesado da criada era o verdadeiro símbolo da caridade; ali estava a junção de alimentação e a mor que encontramos nas alegorias homônimas.

É importante salientar a necessidade da comparação na apreensão das alegorias de Giotto. O fato de ele produzir por recortes e orga nizações não era em vão; havia, certamente, uma intenção de causar algo no leitor Se conferirmos mais uma vez o tratado de pintura de Alberti, veremos que a comparação é teorizada por ele:
O marfim e a prata são brancos, mas postos ao lado do cisne e da neve parecerão pálidos. Por essa razão, na pintura as coisas aparecem extremamente brilhantes onde existe uma boa proporção de branco com preto, semelhante ao que nas coisas vai do luminoso ao sombreado. Assim, essas coisas todas se conhecem por comparação. A comparação tem em si essa força, a de mostrar nas coisas o que é mais, o que é menos, o que é igual. (ALBERTI, 2014, p. 87)

Analogamente, a Caridade de Giotto parece sem caridade, mas, posta próxima à Inveja, deixou transparecer sua caridade. Se pensarmos na comparação entre Françoise e a criada, perceberemos que aquela, pela ausência do ventre, ou seja, pela ausência do símbolo de caridade, faz com que esta tenha sua caridade evidenciada.

Em uma confirmação da importância da comparação entre os vícios e virtudes para a apreensão dos significados, basta atentarmos para a disposição dos afrescos na própria capela. Theodore Johnson descreve que há uma

luta entre as paredes através das quais o espectador passa conforme se movimenta para baixo na capela, e, de fato, a luta ou tensão realmente tem lugar dentro do espectador. As virtudes e os vícios são deste mundo e, portanto, estão no nosso nível na capela. Assim que o espectador deixa a

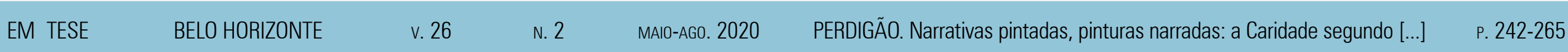

Teoria, Crítica Literária, outras Artes e Mídias 
42. (Tradução minha).

43. "The space of the Vices and Virtues is that of the viewer, for hrough which the spectator passes as he moves down the chapel, and indeed, the struggle or tension really takes places within the spectator. The virtues and the vices are of this world and are therefore on our level in the chapel. As the spectator leaves the chapel, he must move between these figures and pass under the Christ Judge of the Last Judgment. Following the traditiona conographic pattern, the Vices and Hell are on Christ's left, or in this chapel, the windowless north wall; the Virtues and Heaven are on his right, the south wall whose light illuminates the chapel. In turn these frescoes should illuminate the spectator, or at least cause the spectator to examine his own conscience." (JOHNSON, 1973, p. capela, ele precisa se mover entre essas figuras e passar debaixo da de Cristo no Juízo Final. Seguindo o padrão ico nográfico tradicional, os Vícios e o Inferno estão à esquerda de Cristo, ou, nessa capela, na parede norte, sem janelas. Já as Virtudes e o Céu estão à direita de Cristo, na parede sul cuja luz ilumina a capela. Os afrescos, então, têm o papel de iluminar o espectator ou, pelo menos, causar nele um exame de consciência. ${ }^{42}$ (JOHNSON, 1973, p. 170-1) ${ }^{43}$

Isso confirma que o recorte e a organização feitas por Marcel em sua sala de estudos, colocando Caridade e Inveja próximos, reproduzem a organização dos afrescos na capela de Arena. Além disso, Johnson explica que a iluminação recai sobre as virtudes quando a pessoa sai da capela, provocando, assim, um exame de consciência. $O$ fato de essa iluminação se dar na saída explica o porquê de a apreciação dos afrescos de Giotto e, também, da criada de cozinha, por Marcel, ter se dado após tanto tempo, haja vista o narrador ser adulto e estar retomando memórias da infância.

Com isso, as alegorias de Giotto passam a ter uma função pedagógica:

A relação entre os significados próprio e literal da alegoria que podem ser chamados respectivamente de 'alegorema" $\mathrm{e}$ "alegorese" (da mesma forma que se distinguem "noema" e "noese") não é meramente uma relação de não-coincidência. A dissonância semântica vai mais além. Concentrando sua observação nos detalhes pictóricos da Inveja, ele não tem, diz Marcel, "tempo para pensamentos invejosos". Daí a eficácia didática da alegoria, uma vez que nos faz esquecer os vícios que se propõe representar[...] Na realidade acontece que, no caso da Inveja, a mente é desviada na direção de algo até mais ameaçador que o vício, ou seja, a morte. Do ponto de vista retórico e estrutural, entretanto, tudo o que importa é que a representação alegórica conduz a um significado que diverge do inicial, a ponto de excluir sua manifestação. (DE MAN 1996, p. 92-3).

Marcel aprendeu a fazer uma leitura das alegorias não só nas obras de arte, mas em sua realidade. Conseguiu estabelecer compa rações, a tentar-se a símbolos e, assim, aprendeu que, antes de uma conclusão sobre a ausência de algo em uma imagem, é necessária uma leitura mais atenta de todos os detalhes.

\section{CONCLUSÃO}

Uma vez que iniciei o texto com a discussão sobre escrita e imagem, após toda a leitura de como foi a interpretação do afresco de Giotto no romance de Proust, 
vale citar as provocações de Paul de Man e Arthur Schopenhauer a esse respeito:

Uma leitura literal do afresco de Giotto nunca levaria à descoberta de seu significado, já que todas as propriedades representadas aponta m numa direção diferente. Só sabemos o significado da alegoria porque Giotto, substituindo a representação pela escrita, o deixou bem claro na moldura superior de sua pintura: KARITAS. Aceitamos o significado próprio a través de um ato direto de leitura, e não pela leitura oblíqua da alegoria. (DE MAN, 1996, p. 95)

De Man apresenta que seria imprescindível a leitura da legenda de Giotto para a compreensão da alegoria, enquanto Schopenhauer alega que uma simples palavra provocaria o mesmo efeito no leitor que o conta to com uma imagem:

Não quero com isso afirmar que uma imagem alegórica, justamente no que se refere a tal característica, não desperte impressão vivaz na mente: mas tal impressão também seria, sob condições iguais, despertada por uma inscri- ção. Por exemplo, se na mente de um homem se enraíza duradoura e fixamente desejo de glória, na medida em que a considera como sua justa propriedade que lhe é postergada apenas porque ainda não providenciou os documentos de sua posse, e se agora aparece diante de si o gênio da glória com sua coroa de louros, então toda a sua mente será estimulada e suas forças colocadas em a tividade. No entanto, o mesmo também ocorreria se subitamente visse num muro de maneira clara e em grandes caracteres a palavra "glória". (SCHOPENHAUER, 2005, p. 315-6).

Após as a nálises de No Caminho de Swann das várias alegorias de caridade e da relação com a obra de Giotto com a de Dante Alighieri, devo discordar de ambos os autores. De Paul de Man discordo porque, no fim das contas, o reconhecimento da caridade na Caridade de Giotto se deu pela comparação com outra imagem, o que teve como consequência, ta mbém, a a tenção dele ao símbolo que a própria criada carregava: o ventre. $\mathrm{O}$ apelido dado por Swann à criada não foi o suficiente para que ele a identificasse como Caridade, assim como a escrita sobre a moldura não foi suficiente para que ele se convencesse da presença de sentimentos caridosos na alegoria de Giotto. Da mesma forma, se Marcel visse a palavra "Caridade" escrita na parede em letras grandes e nítidas, não haveria toda essa reflexão que, por fim, foi didática, a ponto de, anos depois, o narrador já crescido ter colocado essa alegoria em suas memórias de infância. Saindo do ficcional, pensemos na relação do autor, Marcel Proust, com a Caridade de Giotto. O primeiro contato dele foi com a escrita, porém não a escrita 
simplesmente da palavra "CARIDADE", em acordo com o que sugere Schopenhauer, mas com uma écfrase no texto de Ruskin. A partir disso, a reflexão dele sobre os afrescos é despertada, até mesmo a ponto de ele viajar para conferi-los pessoalmente. Anos depois, ele faz o narrador de Em Busca do Tempo Perdido ser um adulto que ainda se lembra da criada de cozinha e da alusão feita por Swann quando ele era criança. Isso me leva a concluir que tanto a escrita quanto a imagem podem causar o mesmo efeito, sim, particularmente se a escrita for uma écfrase e a imagem for resultante de uma compositio. É necessário que o pintor, mais do que dar conta das movimentações da alma nas representações, se atente aos símbolos que acompanharão a personificação em sua alegoria. Analoga mente, é necessário que o escritor se dedique à descrição dos símbolos em sua écfrase das pinturas, seja de uma pintura já vista algures, seja da pintura que ele mesmo elaborou em sua própria mente.

\section{REFERÊNCIAS}

ALBERTI, Leon Battista. Da Pintura. Tradução de Antonio Silveira Mendonça. Campinas: Editora UNICAMP, 2014.
ALIGHIERI, Dante. Vida Nova. In: PIGNATARI, Décio (Org.) Retrato do Amor quando Jovem: Dante, Shakespeare, Sheridan, Goethe. São Paulo: Companhia das Letras, 2001.

ALIGHIERI, Dante. Vita Nova. Segrate: Mondadori, 1999.

ASSMANN, Aleida. Espaços da recordação: formas e transformações da memória cultural. Campinas: Editora da UNICAMP, 2018

BAGOLIN, Luiz Armando. Apresentação. In: BAXANDALL, Michael. Giotto e os oradores: As Observações dos Humanistas Italianos sobre Pintura e a Descoberta da Composição Pictórica (1350-1450). Tradução de Fábio Larrson. São Paulo: Editora da Universidade de São Paulo, 2018.

BAXANDALL, Michael. Giotto e os oradores: As Observações dos Humanistas Italianos sobre Pintura e a Descoberta da Composição Pictórica (1350-/1450). Tradução de Fábio Larrson. São Paulo: Editora da Universidade de São Paulo, 2018.

BEAUTHÉC, Nadine. Les Promenades de Marcel Proust. Paris : Éditions du Chêne, 1997.

BENJAMIN, Walter. Origem do drama trágico alemão. Belo Horizonte: Autência, 2016. 
CHASTEL, André A Arte Italiana. São Paulo: Martins Fontes, 1991

CHERNOWITZ, Maurice E. Proust and painting. New York International University Press, 1945.

DE MAN, Paul. Alegorias da leitura: Linguagem Figurativa em Rousseau, Niezstche, Rilke e Proust. Tradução de Lenita Esteves. Rio de Janeiro: Imago 1996.

FAURE, Élie. História da Arte: A Arte do Renascimento.

Tradução de Vitorino Nemésio. Lisboa: Estúdios Cor Lisboa 1949

HANSEN, João Adolfo. Alegoria: construção e interpretação da metáfora. Campinas: Hedra, 2006.

HANSEN, João Adolfo. Categorias epidíticas da écfrase. REVISTA USP, São Paulo, n.71, p. 85-105, 2006

JOHNSON, J. Theodore. Proust and Giotto: Foundations for an Allegorical Interpretation of $A$ la recherche du

temps perdu. In: PRICE, Larkin B. Marcel Proust: A Critical

Panorama. Chicago: University of Illinois Press, 1973.
KARPELES, Eric. Paintings in Proust: A visual Companion to "In Search of Lost Time". London: Thames and Hudson, 2008

MARTINS, Paulo. Uma visão periegemática da écfrase. Revista Classica. Rio de Janeiro, v. 29, n. 2, p. 163-204, 2016

PANOFSKY, Erwin. Significado nas Artes Visuais. São Paulo: Editora Perspectiva, 1979

PROUST, Marcel. Du côté de chez Swann. Paris: Flammarion, 1987

PROUST, Marcel. No caminho de Swann. Tradução de Mário Quintana. São Paulo: Abril Cultural, 1979.

RUSKIN, John. Giotto and his works in Padua. Champaign: Book Jungle, n/d. SCHOPENHAUER, Arthur. 0 mundo como vontade e representação. Tradução de Jair Barbosa. São Paulo: Editora UNESP, 2005.

Recebido em: 26/02/2020. Aceito em: 23/11/2020 